\title{
Remediation of Aviation Kerosene-Contaminated Soil by Sophorolipids from Candida bombicola CB 2107
}

\author{
Torsha Goswami ${ }^{1,2}$, Filip M. G. Tack ${ }^{2, *}$, , Lenka McGachy ${ }^{1}\left(\mathbb{D}\right.$ and Marek Šír ${ }^{1}$ \\ 1 Department of Environmental Chemistry, University of Chemistry and Technology, Prague, Technićka 5, \\ 16628 Praha 6, Czech Republic; toyarosha@gmail.com (T.G.); Lenka.hokrova@vscht.cz (L.M.); \\ marek.sir@vscht.cz (M.Š.) \\ 2 Department of Green Chemistry and Technology, Ghent University, Coupure Links 653, \\ B-9000 Gent, Belgium \\ * Correspondence: filip.tack@ugent.be
}

Received: 30 December 2019; Accepted: 7 March 2020; Published: 13 March 2020

\begin{abstract}
Yeast-derived biosurfactants may substitute or complement chemical surfactants as green reagents to extract petroleum hydrocarbons from contaminated soil. The effectiveness of contaminant clean-up by sophorolipids was tested on kerosene-contaminated soil with reference to traditional synthetic surfactants. The sophorolipids produced by the yeast Candida bombicola CB 2107, cultivated with the carbon sources $10 \mathrm{~g} / \mathrm{L}$ glucose and $10 \mathrm{~g} / \mathrm{L}$ rapeseed oil, were most effective in contaminant removal. This biosurfactant revealed a critical micelle concentration of $108 \mathrm{mg} / \mathrm{L}$ which was close to that of Triton X-100 (103 mg/L), the synthetic surfactant considered as reference. It outperformed Triton X-100 in reducing kerosene concentrations (C10-C40) in contaminated soils. In a soil initially containing $1080 \mathrm{mg} / \mathrm{kg}$ of $\mathrm{C} 10-\mathrm{C} 40$, the concentration was reduced to $350 \mathrm{mg} / \mathrm{kg}$ using the biosurfactant, and to $670 \mathrm{mg} / \mathrm{kg}$ using Triton-X. In the soil with initial concentration of $472 \mathrm{mg} / \mathrm{kg}$, concentrations were reduced to 285 and $300 \mathrm{mg} / \mathrm{kg}$ for biosurfactant and Triton X-100, respectively. Sophorolipids have the potential to replace synthetic surfactants. Properties and performance of the biosurfactants, however, strongly differ depending on the yeast and the growing conditions during production.
\end{abstract}

Keywords: petroleum hydrocarbons; yeast-derived biosurfactant; bioremediation

\section{Introduction}

Petroleum hydrocarbons are common environmental pollutants of concern. They contaminate soil and water primarily during oil spills and eventually enter the food web. Remediation of hydrocarbon-contaminated soils conventionally is achieved through biological degradation for moderate contamination, or through physico-chemical soil-washing techniques [1]. Surfactants aid in the removal of pollutants adsorbed to the soil by the stimulation of mass transport of these pollutants from the soil to the aqueous phase. This is achieved by the reduction of surface tension and micellar solubilisation, emulsification of liquid pollutant and facilitated transport [2]. Due to the adsorption of the molecules of surfactants on the soil contaminant surface, a repulsion occurs between the head groups of the surfactants and the soil particles. This facilitates the removal of contaminant molecules from the soil surface in extractive soil remediation $[3,4]$.

Regulations increasingly restrict the use of chemical agents for soil/water recovery [5], favouring more sustainable green remediation approaches. The natural biodegradation of hydrocarbons in soil has been reported to be remarkably enhanced by the in situ production of biosurfactants derived from soil microorganisms or their addition $[2,6]$. Biosurfactants may be used as surface-active soil-cleaning agents that are more environmentally friendly for physico-chemical soil washing. 
A variety of bacteria, yeast and filamentous fungi produce amphiphilic biological compounds, known as biosurfactants, extracellularly or as part of their cell membrane [7-10]. They can be of low molecular weight such as glycolipids or lipopeptides, or of high molecular weight such as exocellular polymeric surfactants. The latter include polysaccharides, lipopolysaccharides, proteins, lipoproteins or complexes of these biopolymers [11]. Sophorolipids form a class of glycolipid biosurfactants isolated from non-pathogenic yeasts such as Candida bombicola. The non-pathogenic nature of sophorolipids and the very high yield of over $400 \mathrm{~g} / \mathrm{L}$ that can be achieved nowadays is increasingly making it a more attractive alternative over petroleum-based surfactants $[12,13]$. The two yeasts most commonly studied for their ability to produce sophorolipids are Candida bombicola and Candida lipolytica [14]. The remarkable differences between structural classes of sophorolipids are the basis of the wide variation in their physicochemical properties. For example, the sophorolipids synthesized by Candida bombicola actually are a mixture of related molecules with different chain length, saturation and hydroxylation in the fatty acid part and different patterns of lactonisation and acetylation [12]. These compounds are readily biodegradable and have low cytotoxicity levels [15], properties that are very favourable for application in soil contaminant remediation.

At present, the expenses associated with biosurfactant-based soil remediation are high. Production cost of sophorolipids are in the $2-5 € / \mathrm{kg}$ range, which is higher than that of ethoxylate or alkyl polyglycoside (US\$ 1-3/kg) [16]. The cost of biosurfactant production has to be brought down to $£ 1.70 / \mathrm{L}$ to outperform chemical surfactants in the market [17]. More economical ways of biosurfactant production must be explored, as this is the primary hurdle in the way of their commercialisation. Until now, rhamnolipids and surfactin, a cyclic lipopeptide, are the only commercially available biosurfactants [18]. Cheaper substrates such as dairy and distillery wastes, and sugarcane molasses, could be used for the biosurfactant production process. Also recycling of surfactants is considered to reduce the overall costs of remediation [19]. In the year 2012, the total production of surfactants was approximately 12 million tons, of which biosurfactant production had a share of 3.5 million tons [20]. Patents for some biosurfactant producing microorganisms such as Candida bombicola ATCC2214, have also been issued in recent years [21]. This shows the growing significance of the commercial application of biosurfactants. Significant biotechnological advances in biosurfactant technology can bring down the production costs and, thereby, support large-scale production [16].

The focus of this research is on application of biosurfactants, in particular sophorolipids, in the remediation of soil contaminated with petroleum hydrocarbons. This study examines the potential of sophorolipids for extractive cleaning of oil contaminated soils, with reference to conventional synthetic surfactants. Sophorolipids were produced using yeasts, Candida and Yarrowia, grown in different conditions. Surface active properties of the resulting biosurfactants were tested, and selected products were explored for their efficacy in solubilizing aviation kerosene from contaminated soil. The principal objectives were (i) to perform a comparative study between synthetic surfactants and biosurfactants in terms of their effectiveness to remediate soil contaminated with petroleum hydrocarbons, (ii) to study the residual organic contamination in the test soils after soil washing, and (iii) to observe the influence of yeast cultivation conditions on hydrocarbon remediation.

\section{Materials and Methods}

\subsection{Materials}

\subsubsection{Surfactants and Chemicals Used}

Non-ionic synthetic surfactants, Triton X-100, Tween 80 and Brij 58, were purchased from Sigma-Aldrich, Inc. They were laboratory grade and storable at room temperature. Triton X-100 is characterised by a polyethylene oxide chain as its hydrophilic group and an aromatic hydrocarbon as its hydrophobic group. Tween 80 is a mixture of polyoxyethylene ethers and has emulsifier properties, whereas Brij 58 is polyethylene glycol hexadecyl ether. 
Biosurfactants were obtained by cultivation of two strains of non-pathogenic sophorolipid-producing yeasts in different conditions. Yarrowia lipolytica was isolated from a crude oil lagoon in the southern Czech Republic by EPS biotechnology s.r.o. (Kunovice, Czech Republic) Candida bombicola CB 2107 was purchased from the AV ČR, Czech Academy of Sciences (Prague, Czech Republic). They were cultured on mineral medium, with the addition of different concentrations of polar (glucose) and nonpolar (rapeseed oil) carbon sources and yeast extract as a nitrogen source, to produce 8 different sophorolipid samples (Table 1).

Table 1. Substrates involved in the production of the sophorolipids.

\begin{tabular}{|c|c|c|c|c|c|}
\hline BS $^{1}$ & Producer Yeast & Glucose $(\mathrm{g} / \mathrm{L})$ & Rapeseed Oil (g/L) & Place of Growth & Yield $(\mathrm{g} / \mathrm{L})^{2}$ \\
\hline A & Candida bombicola CВ 2107 & 1 & 1 & E. Flask ${ }^{3}$ & 0.2 \\
\hline $\mathrm{B}$ & Yarrowia lipolytica & 10 & 10 & E. Flask & 1.3 \\
\hline $\mathrm{C}$ & Yarrowia lipolytica & 10 & 10 & Auto. bio. ${ }^{4}$ & ND \\
\hline $\mathrm{D}$ & Yarrowia lipolytica & 1 & 1 & E. Flask & 1.2 \\
\hline $\mathrm{E}$ & Yarrowia lipolytica & $10^{5}$ & 10 & E. Flask & 5.2 \\
\hline $\mathrm{F}$ & Yarrowia lipolytica & $0^{6}$ & 10 & E. Flask & 0.1 \\
\hline G & Yarrowia lipolytica & $10^{5}$ & 10 & Auto. bio. & ND \\
\hline $\mathrm{H}$ & Candida bombicola CВ 2107 & 10 & 10 & E. Flask & 3.9 \\
\hline
\end{tabular}

To produce the sophorolipids, yeast strains were sub-cultured from agar malt extract to mineral medium (Table 2) along with Difco ${ }^{\mathrm{TM}}$ Yeast Nitrogen Base (BD Biosciences, Heidelberg, Germany) and $10 \mathrm{~g} / \mathrm{L}$ of rapeseed oil. The cultures were kept on an orbital shaker (WiseShake SHO-2D, Witeg Labortechnik $\mathrm{GmbH}$, Wertheim, Germany) at $120 \mathrm{rpm}$ (rotation per minute) for 4 days at room temperature. Yeast from these cultures were inoculated again in the mineral medium $\left(1.8 \times 10^{5}\right.$ $\mathrm{cfu} / \mathrm{mL}$ for Candida bombicola and $4.3 \times 10^{5} \mathrm{cfu} / \mathrm{mL}$ for Yarrowia lipolytica) and cultured for 4 days at room temperature in a bioreactor (Bioscreen Testing Service, Inc., Torrance, CA, USA) with automatic temperature and $\mathrm{pH}$ control. The preculture was incubated for 7 days.

Table 2. Composition of the mineral medium, $\mathrm{pH} 6.5$.

\begin{tabular}{cccc}
\hline Primary Chemicals & Amount (g/L) & Trace Elements & Amount (mg/L) \\
\hline $\mathrm{K}_{2} \mathrm{HPO}_{4}$ & 0.17 & $\mathrm{MnCl}_{2} \cdot 4 \mathrm{H}_{2} \mathrm{O}$ & 1.00 \\
$\mathrm{KH}_{2} \mathrm{PO}_{4}$ & 0.13 & $\mathrm{CaCl}_{2} \cdot 2 \mathrm{H}_{2} \mathrm{O}$ & 0.26 \\
$\left(\mathrm{NH}_{4}\right)_{2} \mathrm{SO}_{4}$ & 0.71 & $\mathrm{FeSO}_{4} \cdot 7 \mathrm{H}_{2} \mathrm{O}$ & 0.60 \\
$\mathrm{MgCl}_{2} \cdot 6 \mathrm{H}_{2} \mathrm{O}$ & 0.34 & $\mathrm{Na}_{2} \mathrm{MoO}_{4} \cdot 2 \mathrm{H}_{2} \mathrm{O}$ & 2.00 \\
$\mathrm{YNB}^{1}$ & 1.17 & & \\
\hline
\end{tabular}

Cultivation of the obtained yeast was continued for $168 \mathrm{~h}$ in mineral medium containing a non-polar (vegetable oil) and a polar (glucose) carbon source in different ratios (Table 1) at $20{ }^{\circ} \mathrm{C}$ temperature. Shaking was performed on a planar shaker at $120 \mathrm{rpm}$. The $\mathrm{pH}$ was 6 , and the oxygen saturation was about $76 \%$ throughout the cultivation.

The biosurfactants were isolated from the growing media using protocols described before [22-24]. After dispersion in an ultrasonic water bath for $15 \mathrm{~min}$, the production medium was subjected to triple extraction during each 10 min using ethyl acetate (p.a. grade, Penta s.r.o., Prague, Czech Republic). The default volume ratio of ethyl acetate to aqueous phase was 1:2, but was increased to 3:1 for treatments with poorly separable emulsions. After each extraction step, the organic phase was transferred to a rotary vacuum evaporator flask to separate the crude surfactant from the ethyl acetate phase. Then, the mixture was transferred to a Petri dish and the residual ethyl acetate was left to evaporate at room temperature under the fume hood. Depending on the conditions of pre-treatment of the production medium, the crude surfactant was contaminated with some oil, which was removed by a hexane wash. 
Pure product was formed as deposits on the petridish walls, or in the form of crystals or gel at the bottom of the dish.

Sodium sulphate $\left(\mathrm{Na}_{2} \mathrm{SO}_{4}\right)$, n-heptane, acetone, pentane and methanol were provided by Penta s.r.o., Prague, Czech Republic. Florisil and 2,3,5-triphenyl tetrazolium chloride (TTC) were provided by Sigma-Aldrich Chemie GmbH, Darmstadt, Germany. All the chemicals were laboratory grade.

\subsubsection{Kerosene-Contaminated Soil}

Kerosene-contaminated soil was sampled from the north-western part of the area surrounding the former airbase in the Hradčany district of Czech Republic near Mimoň. During the years 1940-1989, there were frequent incidents of accidental oil spills which resulted in contamination of soil with different types of fuels, most frequently aviation kerosene. A core of the contaminated soil was sampled at different depths using a stainless steel drill sampler for loose matrices. The soil was sandy and dry from the surface to about $1.5 \mathrm{~m}$ depth. Then, it was a mix of mildly wet sand and clay between $1.5-2.5$ $\mathrm{m}$. Soil from $2.5 \mathrm{~m}$ onwards was completely water-saturated and predominantly clayey. In total, 11 depths were sampled. Three of them were analysed for soil properties (Soil 7: 2.2-2.5 m; Soil 10: 2.8-3 $\mathrm{m}$ and Soil 11: 3-3.1 m). Soil 7 and 11 were selected for the kerosene extraction experiment.

\subsection{Kerosene Extraction Experiments}

In a solubilisation test, the capability of the surfactants to keep kerosene in suspension was tested. To $25 \mathrm{~mL}$ of $500 \mathrm{mg} / \mathrm{L}$ surfactant solution or distilled water (blank) in a $100 \mathrm{~mL}$ Erlenmeyer flasks, 100 $\mu \mathrm{L}$ kerosene was added. The flasks were sealed and shaken at $100 \mathrm{rpm}$ for $3 \mathrm{~h}$ on a digital orbital shaker (WiseShake SHO-2D, Witeg Labortechnik GmbH, Wertheim, Germany), after which $15 \mathrm{~mL}$ of solution was sampled for kerosene analysis (see Section 2.3.4).

Tests to remove kerosene from field-contaminated Hradčany soil involved the surfactants Triton X-100, Tween-80 and the sophorolipids A, B, C, F, H, and samples 7 and 11 of the Hradčany soil. A suspension of $10 \mathrm{~g}$ soil and $50 \mathrm{~mL} 500 \mathrm{mg} / \mathrm{L}$ surfactant solution was shaken for $1 \mathrm{~h}$ at $100 \mathrm{rpm}$. Resulting suspensions were very turbid and were allowed to settle during $24 \mathrm{~h}$ before analysis of kerosene content (see Section 2.3.4).

\subsection{Characterisation and Chemical Analysis}

\subsubsection{Surfactant Characteristics}

Surface tension was determined according to the ring-tearing method $[25,26]$ with a tensiometer (K6, Kruss GmbH, Hamburg, Germany) at room temperature. Synthetic surfactants and dilutions of sophorolipid samples A-H (10, 50, 100, 250 and $500 \mathrm{mg} / \mathrm{L})$ were tested. Purified surfactants were dissolved in demineralized water to achieve appropriate concentrations of the required surfactant solutions. A graph of surfactant concentrations against corresponding surface tension values was plotted to derive the CMC for each surfactant [27]. CMC (mg/L) was determined as the point where the progressive decrease in surface tension changes to a constant value by estimating regression lines for each of the sections using linear regression and determining their intersection point [28].

In an oil-spreading experiment [29], $20 \mathrm{~mL}$ of distilled water and $20 \mu \mathrm{L}$ kerosene were added into a $10 \mathrm{~cm}$ Petri dish. Then, $200 \mu \mathrm{L}$ surfactant $(500 \mathrm{mg} / \mathrm{L}$ ) was slowly added. The diameter of the clearing zone reflected the surfactant activity. Emulsion activity was determined according to a published procedure [30] with some modifications. A volume of $0.5 \mathrm{~mL}$ of oil substrates was added to $2 \mathrm{~mL}$ of surfactant solution $(500 \mathrm{mg} / \mathrm{L}$ ), and the mixture was vortexed (IKA Vortex Genius3, Fisher Scientific, Schwerte, Germany) at full speed for $2 \mathrm{~min}$. The height of the emulsion layer and the total height, i.e., the sum of height of oil layer, emulsion layer and aqueous layer were measured after keeping the test tubes undisturbed for $24 \mathrm{~h}$. The emulsion index $\left(E_{24}\right)$ was calculated as the ratio between these two measures [31]. 


\subsubsection{Soil Properties}

To determine porosity, a volume of $20 \mathrm{~mL}$ dry soil was measured in a $50 \mathrm{~mL}$ test tube. Distilled water was added cautiously until the soil was saturated with water. The final volume of distilled water required for the complete saturation of soil was recorded. Soil porosity was calculated as the ratio between the volume of water required to saturate the soil and the soil volume. Soil $\mathrm{pH}$ was determined in an extract of $5 \mathrm{~mL}$ soil in $30 \mathrm{~mL}$ distilled water, which was vigorously shaken for $5 \mathrm{~min}$ and then left undisturbed for $2 \mathrm{~h}$. $\mathrm{pH}$ was measured at $25^{\circ} \mathrm{C}$ using a digital $\mathrm{pH}$ meter (GMH 3530, Greisinger Electronic, Regenstauf, Germany) [32].

\subsubsection{Kerosene Extraction from Contaminated Soil}

To $10 \mathrm{~g}$ soil in glass bottles with stoppers, $20 \mathrm{~mL}$ acetone followed by $10 \mathrm{~mL}$ heptane were added. The bottles were thoroughly shaken after each addition. The sample was placed in an ultrasonic water bath (PSO4000A, Labio, Prague, Czech Republic) for $15 \mathrm{~min}$ and then left to settle. The supernatant solution was decanted into a borosilicate glass separator funnel and extracted two consecutive times with $50 \mathrm{~mL}$ of distilled water. The resulting emulsion was transferred to $30 \mathrm{~mL}$ glass vials and analysed for kerosene.

\subsubsection{Kerosene Analysis}

Kerosene was analysed by gas chromatography as the sum of the concentrations of the $\mathrm{C} 10-\mathrm{C} 40$ fractions. To $30 \mathrm{~mL}$ glass scintillation vials, $15 \mathrm{~mL}$ sample and $5 \mathrm{~mL}$ heptane were added. Vials were manually shaken for $10 \mathrm{~min}$ and left undisturbed for $1 \mathrm{~h}$ to allow the settling of phases. After $1 \mathrm{~h}$, the extracted contaminant in heptane phase was transferred into fresh scintillation vials. After addition of $0.1 \mathrm{~g} \mathrm{Na}_{2} \mathrm{SO}_{4}$ the mixture was hand shaken for $2 \mathrm{~min}$. The $\mathrm{Na}_{2} \mathrm{SO}_{4}$ removes water and breaks emulsions, resulting in a clear supernatant. Subsequently, polar organic matter was removed by adding $0.1 \mathrm{~g}$ of Florisil, followed by manual shaking. A sample of the clear heptane phase was pipetted into $2 \mathrm{~mL}$ glass vials and analysed using a Master VH gas chromatograph (DANI Instruments, Cologno Monzese MI, Italy) equipped with a flame ionisation detector (FID) and a Rxi-5HT capillary column with dimensions (length, internal diameter and bead diameter) $15 \mathrm{~m}, 0.25 \mathrm{~mm}, 0.25 \mu \mathrm{m}$ (Restek Corporation, Bellefonte, PA, USA). Conditions of GC analysis were as follows: splitless injection, injector temperature: $320^{\circ} \mathrm{C}$; temperature program: $50^{\circ} \mathrm{C}$ for $2 \mathrm{~min}, 25^{\circ} \mathrm{C} / \mathrm{min}$ to $320^{\circ} \mathrm{C}$, hold 7.2 min; carrier gas: $\mathrm{N}_{2}, 25 \mathrm{~mL} / \mathrm{min}$; detector: temperature $330^{\circ} \mathrm{C} ; \mathrm{H}_{2}-40 \mathrm{~mL} / \mathrm{min}$, air $-280 \mathrm{~mL} / \mathrm{min}$.

\subsubsection{Dehydrogenase Activity (DHA)}

Dehydrogenase activity (DHA) is a measure for microbial activity and thus may reflect toxic effects. The four best-performing surfactants, Triton- $X$ and the sophorolipids $\mathrm{A}, \mathrm{C}$ and $\mathrm{H}$ were tested according to [33]. A dilution series of $250 \mathrm{mg} / \mathrm{L}, 500 \mathrm{mg} / \mathrm{L}, 1000 \mathrm{mg} / \mathrm{L}$ and $2000 \mathrm{mg} / \mathrm{L}$ was prepared for each of the selected surfactants. In total, $1850-\mathrm{mL}$ tubes were prepared (4 surfactants at 4 different concentrations, and 2 blanks (distilled water)). Dry, sieved garden soil from the vicinity of the VŠCHT campus $(2 \mathrm{~g})$ was weighed and transferred to each of the tubes. Then, $1 \mathrm{~mL}$ of the surfactant dilutions or distilled water were transferred to the tubes. To each tube, $1 \mathrm{~mL}$ of $2 \%$ TTC (2,3,5-triphenyl tetrazolium chloride) was added. The tubes were wrapped in foil paper and kept overnight. Microbial production of the enzyme dehydrogenase converts TTC to TPF (1,3,5-triphenyl formazan), which causes a red colour that is determined by photometry. After $24 \mathrm{~h}, 10 \mathrm{~mL}$ methanol was added to each of the tubes, shaken and left undisturbed for $1 \mathrm{~min}$. The soil suspensions were then filtered using Whatman's filter paper, and absorbance at $482 \mathrm{~nm}$ was measured using a spectrophotometer (Cintra 101, GBC Scientific Equipment, Melbourne, Australia). Before measurement, the spectrophotometer was calibrated by 
measuring the absorbance of methanol against a blank. All subsequent measurements were taken with the blank as reference. The DHA was calculated as:

$$
a=\frac{\left(c_{\text {sample }}-c_{\text {blank }}\right) V}{m} \times \frac{100}{D M \%} \times \frac{1}{t}
$$

where $a$ is dehydrogenase activity $(\mathrm{mg} / \mathrm{L}), c_{\text {sample }}$ is the concentration of TPF in the sample $(\mathrm{mg} / \mathrm{L}), c_{\text {blank }}$ is the concentration of TPF in the blank $(\mathrm{mg} / \mathrm{L}), V$ is the total volume of solution (= volume of surfactant + volume of TTC + volume of methanol) $(\mathrm{mL}), m$ is the mass of soil $(\mathrm{g}), D M \%$ is the dry matter content of the soil (\%, mass based) and $t$ is the time of incubation, $24 \mathrm{~h}$. The DHA was expressed in $\mathrm{mg} /(\mathrm{g} \mathrm{h})$.

\section{Results and Discussion}

\subsection{Characteristics and Behaviour of the Tested Surfactants}

A low surface tension favours micelle formation and subsequent solubilisation of the contaminant. The critical micelle concentration (CMC) indicates a minimum concentration of the surfactant at which the contaminant removal would become efficient. The biosurfactants $\mathrm{A}$ and $\mathrm{H}$ reduced the surface tension most strongly, to low values of $37 \mathrm{mN} / \mathrm{m}$ and below (Figure 1).

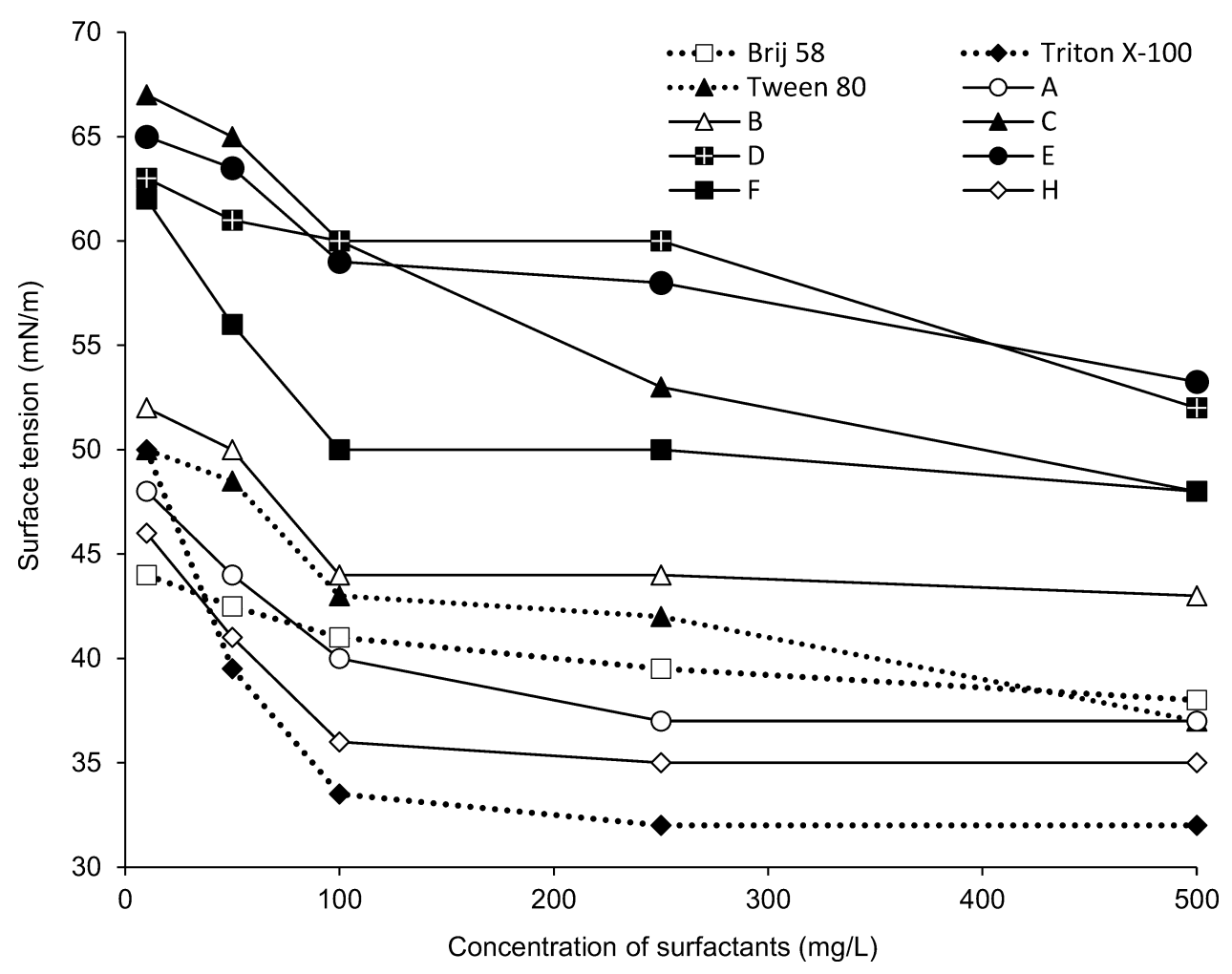

Figure 1. Surface tension $(\mathrm{mN} / \mathrm{m})$ as a function of surfactant concentrations $(\mathrm{mg} / \mathrm{L})$.

These values were in the range of those of the synthetic surfactants. For example, Triton X-100 revealed a minimum surface tension of $32 \mathrm{mN} / \mathrm{m}$ (Figure 1). This suggests that the effectiveness in contaminant clean-up of biosurfactants $\mathrm{A}$ and $\mathrm{H}$ potentially might be comparable with that of the synthetic surfactants. Surface tension for the biosurfactant $G$ was, at about $65 \mathrm{mN} / \mathrm{m}$, quite high compared to the surface tension for corresponding concentrations of the other surfactants. Accordingly, $\mathrm{G}$ was excluded from further tests. The CMC values for Triton X-100 $(103 \mathrm{mg} / \mathrm{L})$ and $\mathrm{H}(108 \mathrm{mg} / \mathrm{L})$ were comparable. This finding was significant as Triton $\mathrm{X}-100$ is known to be an effective surfactant for hydrocarbon remediation. 
In the oil-spreading test, biosurfactant $H$ gave a clear zone with a diameter of $7.6 \mathrm{~cm}$, the largest among the biosurfactants tested and comparable to the $8 \mathrm{~cm}$ observed for Triton X-100 (Table 3). This suggests that $\mathrm{H}$ may be equally effective for oil removal as the synthetic detergent Triton X-100. C did not form a clear zone under the tested conditions.

Table 3. Clear zone diameter for oil spreading test in surfactant solutions (500 mg/L).

\begin{tabular}{cccccccc}
\hline Surfactant & A & B & C & F & H & Tween 80 & Triton X-100 \\
\hline Diameter $(\mathbf{c m})$ & 6.7 & 4 & 0 & 1.8 & 7.6 & 5 & 8 \\
\hline
\end{tabular}

The emulsification index, $E_{24}$ was determined for crude oil, besides kerosene, because the test soil had a contamination profile similar to C10-C40. With crude oil, the $E_{24}$ values were comparable between the biosurfactants, with the highest value, at $18 \%$, recorded for A. Triton X-100, in contrast, gave a quite low value of $5.9 \%$ (Table 4 ).

Table 4. Emulsification index $E_{24}$ of different surfactants (500 mg/L solutions) tested with crude oil and kerosene.

\begin{tabular}{ccccccccc}
\hline Surfactant & A & B & C & F & H & Triton X-100 & Tween 80 & Control \\
\hline $\boldsymbol{E}_{\mathbf{2 4}}(\%)$ with crude oil & 17.7 & 15.7 & 15.7 & 13.7 & 13.7 & 5.9 & 13.7 & 15.7 \\
$\boldsymbol{E}_{\mathbf{2 4}}(\%)$ with kerosene & 4.4 & 2.1 & 2.1 & 1.1 & 4.3 & 22 & 6.1 & 4.4 \\
\hline
\end{tabular}

For kerosene, the highest $E_{24}(22 \%)$ was found for Triton X-100 whereas the biosurfactants A and $\mathrm{H}$ revealed considerably lower values of about $4.4 \%$. This illustrates that the emulsification index markedly depends on the oil type. The emulsifying property of a surfactant is reflected in its foaming effect. A low surface tension favours foam formation, but does not necessarily guarantee a good response to other important features like solubilisation. There are other governing factors for the assessment of the surfactant interactions with the contaminant, such as molecular weight, micellar weight, shape of the micelles, etc.

\subsection{Solubilisation Test and Soil-Washing Tests with Hradčany Soil}

The capacity of a surfactant to retain hydrophobic hydrocarbon contamination in suspension is an important property for application in extractive soil cleaning or enhanced bioremediation. In the test in which all surfactants were employed in a concentration of $500 \mathrm{mg} / \mathrm{L}$, biosurfactant $\mathrm{H}$ performed best, keeping $45 \mathrm{mg} / \mathrm{L}$ of kerosene (C10-C40) in emulsion. The synthetic surfactant performed second best, closely followed by biosurfactants A and B (Table 5). The weakest performing biosurfactant, E, kept only $30 \%$ in solution. The variability existing among the biosurfactants produced by Yarrowia lipolytica (B-F) emphasized the important influence of cultivation conditions on the quality of the produced sophorolipids.

Table 5. Aqueous solubility of kerosene (C10-C40) in solutions of the different surfactants (500 mg/L).

\begin{tabular}{ccccccccc}
\hline Surfactant & A & B & C & D & E & F & H & Triton X-100 \\
\hline $\mathbf{c}(\mathbf{C} 10-C 40)(\mathbf{m g} / \mathrm{L})$ & 24 & 28 & 15 & 21 & 9 & 18 & 45 & 30 \\
\hline
\end{tabular}

Properties of soil from the contaminated Hradčany site are given in Table 6. There was a clear decreasing trend in porosity with depth (Table 6). A decrease in porosity would make it more difficult for the surfactant to enter soil pores and remove the hydrophobic contaminants. Moreover, the initial concentrations of contaminants were higher at greater depths (Table 6). The predominantly clayey soil favoured increased adsorption and lesser diffusion of the hydrophobic contaminants. 
Table 6. Properties of the tested soils samples.

\begin{tabular}{cccc}
\hline & Soil 7 & Soil 10 & Soil 11 \\
\hline Depth $(\mathbf{m})$ & $2.2-2.5$ & $2.8-3$ & $3-3.1$ \\
Texture & sand/clay & clay & clay \\
Moisture content $(\% \mathbf{~ m} / \mathbf{s})$ & 10.4 & 14.5 & 16.0 \\
$\mathbf{p H ~}\left(\mathbf{2 5}{ }^{\circ} \mathbf{C}\right)$ & 6.14 & 5.52 & 5.97 \\
Porosity (\% volume of pores) & 38 & 25 & 25 \\
Initial c(C10-C40) $(\mathbf{m g} / \mathbf{k g})$ & 472 & 837 & 1081 \\
\hline
\end{tabular}

Soil treatment with biosurfactant $\mathrm{H}$ resulted in maximum transfer of contaminants from the soil to the liquid phase (Figure 2a) and, accordingly, the lowest residual contaminant concentration in soil (Figure $2 b$ ). Overall, all selected biosurfactants were at least equally effective in contaminant removal as the synthetic surfactants. Washing with $\mathrm{H}$ reduced the C10-C40 concentration from $472 \mathrm{mg} / \mathrm{kg}$ to $283 \mathrm{mg} / \mathrm{kg}$ in sample 7, which corresponds to a reduction by approximately $40 \%$. For soil 11 , the reduction was from $1081 \mathrm{mg} / \mathrm{kg}$ to $350 \mathrm{mg} / \mathrm{kg}$ (approximately 68\%). Next most efficient was Triton X-100, with a removal of $36 \%$ (from $472 \mathrm{mg} / \mathrm{kg}$ to $301 \mathrm{mg} / \mathrm{kg}$ ) and $38 \%$ (from $1081 \mathrm{mg} / \mathrm{kg}$ to $673 \mathrm{mg} / \mathrm{kg}$ ) from the solid phase of soils 7 and 11, respectively. The next best performing biosurfactants were $\mathrm{F}$ with $11 \%$ and $32 \%$ removal and A with $12 \%$ and $20 \%$ reduction, for soil 7 and soil 11 respectively.

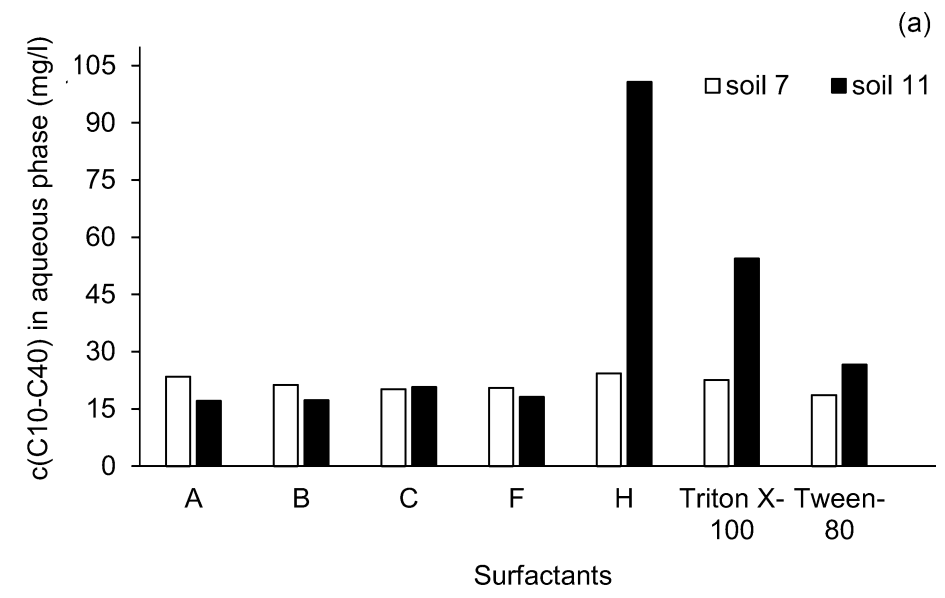

(b)

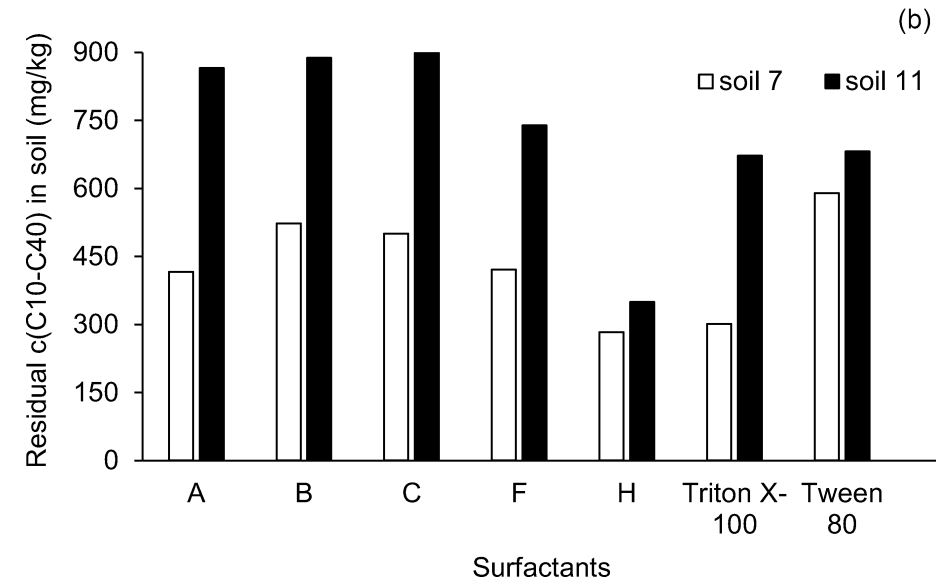

Figure 2. Kerosene, measured as $\mathrm{c}(\mathrm{C} 10-\mathrm{C} 40)$ in $\mathrm{mg} / \mathrm{L}$ in aqueous phase for soil washing (for soil 7 and 11) with surfactants (a) and residual $\mathrm{c}(\mathrm{C} 10-\mathrm{C} 40)$ in soil $(\mathrm{mg} / \mathrm{kg})$ post-washing with surfactants (b). Initial c(C10-C40) of soils 7 and 11 were $472 \mathrm{mg} / \mathrm{kg}$ and $1080 \mathrm{mg} / \mathrm{kg}$ respectively.

Differences in contaminant removal efficiency could be related to the overall cultivation conditions and the producer yeast type. Biosurfactant H (Candida bombicola CB2107) produced in an Erlenmeyer 
flask, with $10 \mathrm{~g} / \mathrm{L}$ of glucose, $10 \mathrm{~g} / \mathrm{L}$ of rapeseed oil and without any nitrogen source, performed best in contaminant removal among all the surfactants. To date, the most successful commercial application is that of Candida bombicola ATCC 22,214 as it produces more than $400 \mathrm{~g} / \mathrm{L}$ sophorolipids [12]. A group of researchers investigated different properties of sophorolipids produced by Candida bombicola, including emulsifying activity, fat and oil solubilisation capacity and their stability at wide ranges of $\mathrm{pH}$, salt concentrations and temperatures, and concluded that this biosurfactant has an important potential for environmental applications [34]. Biosurfactant A (also from Candida bombicola CB2107) cultivated with $1 \mathrm{~g} / \mathrm{L}$ each of glucose and rapeseed oil, devoid of nitrogen source, was less effective in $\mathrm{C} 10-\mathrm{C} 40$ hydrocarbon remediation than $\mathrm{H}$. Hence there could be an influence of concentration of carbon source on the remediation potential of biosufactants. Despite identical production conditions as for $\mathrm{H}$, biosurfactant B (Yarrowia lypolytica) was seen to be less efficient. Biosurfactant $\mathrm{C}$, also by Yarrowia lipolytica, but grown in an automatic bioreactor, and the rest of the conditions being identical to $\mathrm{H}$, also was less efficient than $\mathrm{H}$. Clearly, both strain and production conditions significantly impact the potential efficiency of the produced biosurfactant for extractive soil cleaning. Although Yarrowia, among other yeasts isolated from petroleum-contaminated soil, was shown to be the major organism responsible for the degradation of hydrocarbon [35], novel research with different strains has been limited so far.

\subsection{Dehydrogenase Activity}

Toxicity of the surfactants is an important criterion when striving towards sustainable and environmentally friendly remediation techniques. The dehydrogenase activity (DHA) test did not reveal differences between the surfactants when tested using the Hradčany soil. This may be due to bad conditions for microbial activity in these deeper soil layers, with a lack of nutrients, except for the petroleum hydrocarbons as the carbon source. Therefore, the test was repeated with a biologically active garden soil.

Triton X-100 and biosurfactants A and C revealed an increase in DHA with an increase in surfactant concentrations (Figure 3). DHA activity for biosurfactant $\mathrm{H}$, however, showed no trend. A direct interpretation of high DHA is that the surfactant is less toxic, hence safe for use. An alternative explanation might be that the activation of certain defence mechanisms caused microorganisms to convert TTC to TPF, which was detected as high DHA.

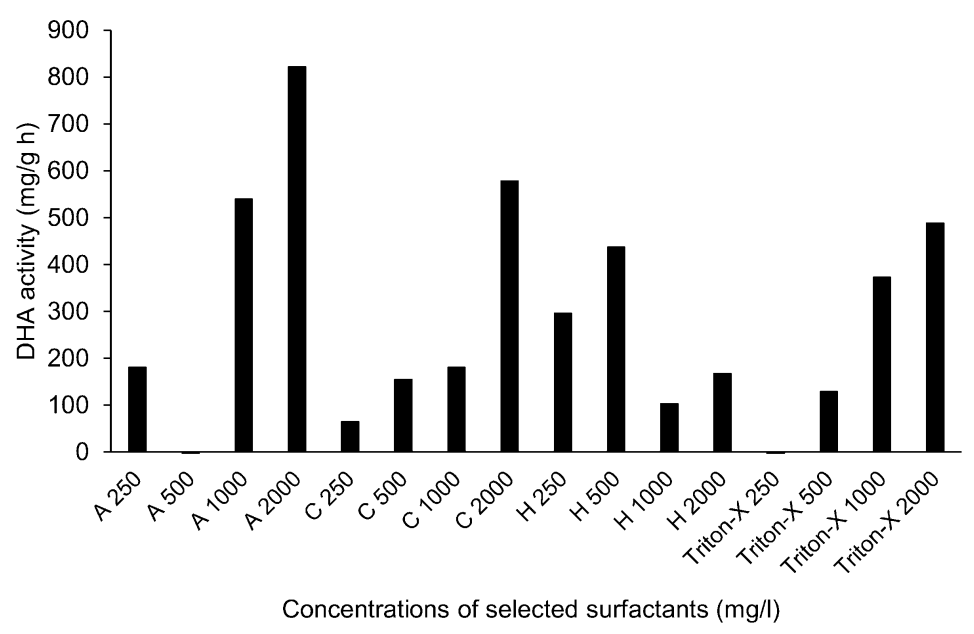

Figure 3. The dehydrogenase activity (DHA, $\mathrm{mg} /(\mathrm{g} h)$ ) of different concentrations (indicated by number in the label, $\mathrm{mg} / \mathrm{L}$ ) of surfactants (identified by letter in the label).

\section{Conclusions}

Some of the studied sophorolipids performed better than the synthetic detergent in solubilizing kerosene. The efficacy of sophorolipid $\mathrm{H}$ to extract hydrocarbons from contaminated soil was higher 
than the synthetic surfactant Triton- $X$, used as reference. The performance of sophorolipids produced by the same yeast strain under different fermentation conditions differed greatly. More experiments should cover different soils and a range of hydrophobic contaminants or mixed contaminations. Future research should delve into the mechanisms behind the differences in performance, and link this to properties and structural features of the produced sophorolipids. This will provide the grounds that will allow us to optimize cultivation conditions for maximum favourable properties of the biosurfactants produced.

Author Contributions: Conceptualization, T.G. and M.̌̌.; methodology, T.G. and M.Š.; software, T.G., M.̌̌. and L.M.; investigation T.G., M.Š. and L.M.; resources, T.G. and F.M.G.T.; writing—original draft preparation, T.G.; writing—review and editing, T.G. and F.M.G.T.; project administration, T.G., M.Š. and F.M.G.T. All authors have read and agreed to the published version of the manuscript.

Funding: This research received no external funding.

Conflicts of Interest: The authors declare no conflict of interest.

\section{References}

1. Tack, F.M.G.; Bardos, P. Overview of Soil and Groundwater Remediation. In Soil and Groundwater Remediation Technologies: A Practical Guide; Ok, Y.S., Rinklebe, J., Hou, D., Tsang, D.C.W., Tack, F.M.G., Eds.; CRC Press: Boca Raton, FL, USA, 2020; pp. 1-12. [CrossRef]

2. Volkering, F.; Breure, A.M.; Rulkens, W.H. Microbiological aspects of surfactant use for biological soil remediation. Biodegradation 1998, 8, 401-417. [CrossRef]

3. Paria, S. Surfactant-enhanced remediation of organic contaminated soil and water. Adv. Colloid. Interf. 2008, 138, 24-58. [CrossRef]

4. Deshpande, S.; Shiau, B.J.; Wade, D.; Sabatini, D.A.; Harwell, J.H. Surfactant selection for enhancing ex situ soil washing. Water Res. 1999, 33, 351-360. [CrossRef]

5. Muthusamy, K.; Gopalakrishnan, S.; Ravi, T.K.; Sivachidambaram, P. Biosurfactants: Properties, commercial production and application. Curr. Sci. 2008, 94, 736-747.

6. Kosaric, N. Biosurfactants and Their Application for Soil Bioremediation. Food Technol. Biotechnol. 2001, 39, 295-304. [CrossRef]

7. Chen, S.Y.; Wei, Y.H.; Chang, J.S. Repeated pH-stat fed-batch fermentation for rhamnolipid production with indigenous Pseudomonas aeruginosa S2. Appl. Microbiol. Biot. 2007, 76, 67-74. [CrossRef] [PubMed]

8. Mata-Sandoval, J.C.; Karns, J.; Torrents, A. High-performance liquid chromatography method for the characterization of rhamnolipid mixtures produced by pseudomonas aeruginosa UG2 on corn oil. $J$. Chromatogr. A 1999, 864, 211-220. [CrossRef]

9. Mata-Sandoval, J.C.; Karns, J.; Torrents, A. Effect of nutritional and environmental conditions on the production and composition of rhamnolipids by P. Aeruginosa UG2. Microbiol. Res. 2001, 155, 249-256. [CrossRef]

10. Rahman, P.K.S.; Gakpe, E. Production, Characterisation and Application of Biosurfactants-Review. Biotechnology 2008, 7, 360-370. [CrossRef]

11. Rosenberg, E.; Ron, E.Z. Natural role of biosurfactants. Environ. Microbiol. 2001, 3, 229-236. [CrossRef]

12. Van Bogaert, I.N.A.; Soetaert, W. Sophorolipids. In Biosurfactants, Part of Microbiology Monographs Book Series; Soberón-Chávez, G., Ed.; Springer: Berlin/Heidelberg, Germany, 2011; Volume 20, pp. 179-210. [CrossRef]

13. Pekin, G.; Vardar-Sukan, F.; Kosaric, N. Production of sophorolipids from Candida bombicola ATCC 22214 using Turkish corn oil and honey. Eng. Life Sci. 2005, 5, 357-362. [CrossRef]

14. Campos, J.M.; Montenegro Stamford, T.L.; Sarubbo, L.A.; de Luna, J.M.; Rufino, R.D.; Banat, I.M. Microbial Biosurfactants as Additives for Food Industries. Biotechnol. Prog. 2013, 29, 1097-1108. [CrossRef] [PubMed]

15. Hirata, Y.; Ryu, M.; Oda, Y.; Igarashi, K.; Nagatsuka, A.; Furuta, T.; Sugiura, M. Novel characteristics of sophorolipids, yeast glycolipid biosurfactants, as biodegradable low-foaming surfactants. J. Biosci. Bioeng. 2009, 108, 142-146. [CrossRef] [PubMed]

16. Santos, D.K.; Rufino, R.D.; Luna, J.M.; Santos, V.A.; Sarubbo, L.A. Biosurfactants: Multifunctional Biomolecules of the 21st Century. Int. J. Mol. Sci. 2016, 17, 401. [CrossRef] 
17. Randhawa, K.K.S.; Rahman, P.K.S.M. Rhamnolipid biosurfactants-Past, present, and future scenario of global market. Front. Microbiol. 2014, 5, 454. [CrossRef]

18. Soberón-Chávez, G.; Maier, R.M. Biosurfactants: A General Overview. In Biosurfactants, Part of Microbiology Monographs Book Series; Soberón-Chávez, G., Ed.; Springer: Berlin/Heidelberg, Germany, 2011; Volume 20, pp. 1-11. [CrossRef]

19. Mao, X.; Jiang, R.; Xiao, W.; Yu, J. Use of surfactants for the remediation of contaminated soils: A review. J. Hazard Mater. 2015, 285, 419-435. [CrossRef]

20. Silva, R.D.; Almeida, D.G.; Rufino, R.D.; Luna, J.M.; Santos, V.A.; Sarubbo, L.A. Applications of biosurfactants in the petroleum industry and the remediation of oil spills. Int. J. Mol. Sci. 2014, 15, 12523-12542. [CrossRef]

21. Sachdev, D.P.; Cameotra, S.S. Biosurfactants in agriculture. Appl. Microbiol. Biot. 2013, 97, $1005-1016$. [CrossRef]

22. Desai, J.D.; Banat, I.M. Microbial production of biosurfactants and their commercial potential. Microbiol. Mol. Biol. Rev. 1997, 61, 41-64. [CrossRef]

23. Daverey, A.; Pakshirajan, K. Production, characterization, and properties of sophorolipids from the yeast Candida bombicola using a low-cost fermentative medium. Appl. Biochem. Biotechnol. 2009, 158, 663-674. [CrossRef]

24. Thaniyavarn, J.; Chianguthai, T.; Sangvanich, P.; Roongsawang, N.; Washio, K.; Morikawa, M.; Thaniyavarn, S. Production of sophorolipid biosurfactant by Pichia anomala. Biosci. Biotechnol. Biochem. 2008, 72, 2061-2068. [CrossRef] [PubMed]

25. Du Noüy, P.L. An interfacial tensiometer for universal use. J. Gen. Physiol. 1925, 7, 625-631. [CrossRef] [PubMed]

26. Chaprão, M.J.; Ferreira, I.N.S.; Correa, P.F.; Rufino, R.D.; Luna, J.M.; Silva, E.J.; Sarubbo, L.A. Application of bacterial and yeast biosurfactants for enhanced removal and biodegradation of motor oil from contaminated sand. Electron. J. Biotechnol. 2015, 18, 471-479. [CrossRef]

27. Sarubbo, L.A.; Luna, J.M.D.; Rufino, R.D.; Brasileiro, P.P.F. Production of a Low-cost Biosurfactant for Application in the Remediation of Sea water Contaminated with Petroleum Derivates. Chem. Eng. Trans. 2016, 49, 523-528. [CrossRef]

28. Morais, I.M.C.; Cordeiro, A.L.; Teixeira, G.S.; Domingues, V.S.; Nardi, R.M.D.; Monteiro, A.S.; Alves, R.J.; Siqueira, E.P.; Santos, V.L. Biological and physicochemical properties of biosurfactants produced by Lactobacillus jensenii P6A and Lactobacillus gasseri P65. Microb. Cell Fact. 2017, 16, 155. [CrossRef] [PubMed]

29. Techaoei, S.; Leelapornpisid, P.; Santiarwarn, D.; Lumyong, S.; Mai, C. Preliminary Screening of Biosurfactant-Producing Microorganisms Isolated From Hot Spring and Garages in Northern Thailand. KMITL Sci. Tech. J. 2007, 7, 38-43.

30. Cooper, D.G.; Goldenberg, B.G. Surface-active agents from two Bacillus species. Appl. Environ. Microb. 1987, 53, 224-229. [CrossRef]

31. Urum, K.; Grigson, S.; Pekdemir, T.; Mcmenamy, S. A comparison of the efficiency of different surfactants for removal of crude oil from contaminated soils. Chemosphere 2006, 62, 1403-1410. [CrossRef]

32. Pansu, M.; Gautheyrou, J. Handbook of Soil Analysis: Mineralogical, Organic and Inorganic Methods; Springer: New York, NY, USA, 2006. [CrossRef]

33. Casida, L.E., Jr.; Klein, D.; Santoro, T. Soil Dehydrogenase Activity. Soil Sci. 1964, 98, 371-376. [CrossRef]

34. Daverey, A.; Pakshirajan, K. Sophorolipids from Candida bombicola using mixed hydrophilic substrates: Production, purification and characterization. Colloids Surf. B Biointerface 2010, 79, 246-253. [CrossRef]

35. Chaillan, F.; Le Flèche, A.; Bury, E.; Phantavong, Y.H.; Grimont, P.; Saliot, A.; Oudot, J. Identification and biodegradation potential of tropical aerobic hydrocarbon-degrading microorganisms. Res. Microbiol. 2004, 155, 587-595. [CrossRef] [PubMed]

(C) 2020 by the authors. Licensee MDPI, Basel, Switzerland. This article is an open access article distributed under the terms and conditions of the Creative Commons Attribution (CC BY) license (http://creativecommons.org/licenses/by/4.0/). 